natural variation is nearly always present with monosynaptic volleys. Then, in record 5 , the test shock is thrown in very late in the contraction set up by the conditioning shock, and is now found to be almost completely inhibited. This transient or phasic inhibition is less prominent with low initial tension of the muscle and becomes very much stronger when the contraction starts from a level of good tension. If the sweep is triggered by merely stretching the muscle quickly instead of stimulating it to contract, the phasic inhibition obtained can be just as complete as that set up by a contraction. Part of the inhibition may be peripheral.

The muscle is thus provided with nervous governors, first facilitating its contraction, then putting on the brakes. At least in some animals, both governors may be 'tonic', a fact of great interest for spastic states and the phenomenon of decerebrate rigidity, which hitherto has been interpreted chiefly on the basis of afferent excitation, because adequate methods for the analysis of autogenetic afferent inhibition have not been available. A few references to early important work ${ }^{3,4,5}$ may serve to indicate the background.

\section{RAGNAR GRANTT} V. SUURSOET

Nobel Institute for Neurophysiology,

Karolinska Institutet, Stockholm.

${ }^{2}$ Lloyd, D. P. C., J. Neurophysiol., 6, 111 (1943).

${ }^{2}$ Lloyd, D. P. C., J. Neurophysiol., B, 317 (1943).

${ }^{3}$ Sherrington. C. S., Quart. J. Exp. Physiol., 2, 109 (1909).

'I.iddell, E. G. T., and Sherrington, C. S., Proc. Roy. Soc., B, 96, 212 (1924).

${ }^{5}$ Denny-Brown, D. Proc. Roy. Soc., B, 103, 321 (1928).

\section{Origin and Site of Formation of Fructose in the Fœtal Sheep}

Bacon and Bell ${ }^{1}$ isolated and identified fructose in foetal sheep's blood. This was the first conclusive proof of its existence prenatally. They also showed it

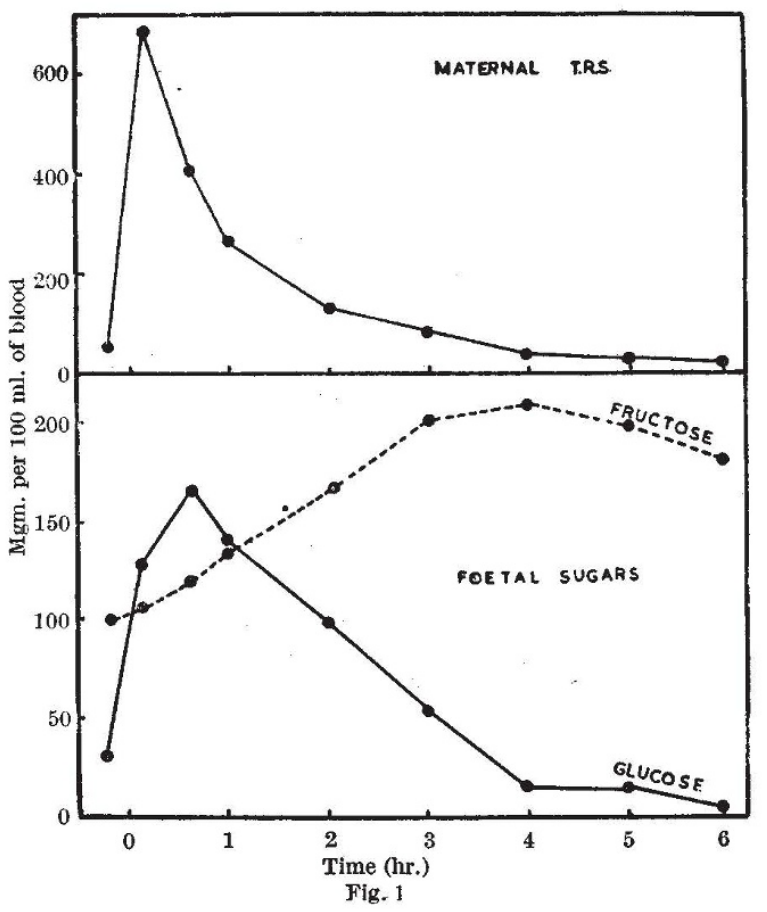

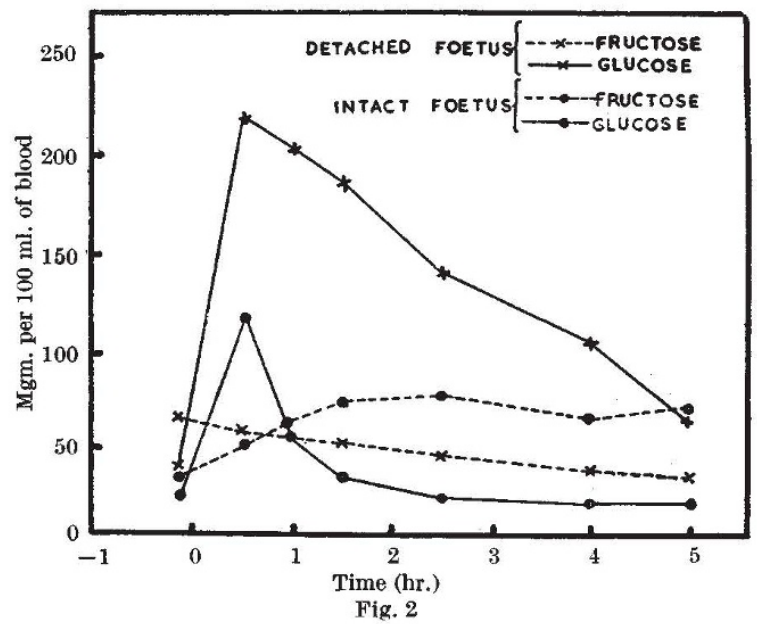

disappears from the blood of the new-born lamb within three days of birth. During 1948 we performed experiments designed to throw some light on the mode of formation and site of origin of this fructose. Cæsarean section was performed under spinal anæsthetic supplemented by pentothal (which we find to be without effect on the blood sugar). The ewe was immersed in saline at $38^{\circ} \mathrm{C}$. into which the fotus was delivered. Blood samples were taken from the maternal dorsalis pedis artery and the umbilical vein. The total reducing substances and the fructose were estimated by the Somogyi-Nelson ${ }^{2}$ method and the $\mathrm{Cole}^{3}$ modification of the Roe's method respectively. The difference was taken as an approximate measure of the glucose.

Glucose (2 gm. per kgm.) given intravenously to the mother always caused a typical sugar tolerance hyperglycæmia reaching $700 \mathrm{mgm}$. Accompanying it there was always a parallel but smaller (150-200 mgm.) curve of fotal hyperglycæmia. In every case there was also a delayed but progressive prolonged fœtal hyperfructosæmia (150-200 mgm.) reaching a maximum in about four hours and then returning to normal after six hours (Fig. 1). The same fotal hyperfructosæmia was obtained on injection of glucose into the umbilical vein. This phenomenon was got with fotuses of all ages from ninety days onwards, the youngest age examined.

If the foetus was detached (being viable) from the placenta $7-10 \mathrm{~min}$. after the umbilical vein was injected with glucose, the rising blood fructose was terminated. This experiment has been performed both on a single foetus and also with twins, both being injected, the attached one serving as a control to the detached (Fig. 2).

It would appear, therefore, that glucose entering the pl centa, whether from the maternal or fœetal circulation, can lead to the formation of fructose, and that this does not occur elsewhere in the fœetal tissues.

\section{A. St. G. Huggets \\ F. L. WARREN \\ V. N. WINTERTON}

Physiology Department,

St. Mary's Hospital Medical School, London, W.2. Feb. 19.

${ }^{1}$ Bacon, J. S. D., and Bell, D. J., Biochem. J., 40, xlii (1946),

${ }^{2}$ Nelson, N., J. Biol. Chem., 153, 375 (1944).

${ }^{3}$ Cole, S. J., described in ref. 1. 